\title{
Innovative Technologies and Logistical Solutions for the Reuse of Demolished Concrete in the Construction of Cement Concrete Pavements
}

\author{
Muscalu Marius-Teodor ${ }^{1, a}$, Andrei Radu ${ }^{1, b}$, Taranu Nicolae ${ }^{1, c}$, \\ Budescu Mihai ${ }^{1, d}$ and Lungu Irina ${ }^{1, e}$
}
${ }^{1}$ Technical University "Gheorghe Asachi" of lasi, Faculty of Civil Engineering and Building Services, Dimitrie Mangeron Blvd. no. 43, 700050, Iasi, Romania, tel. 0040232-23.92.13
amtmuscalu@yahoo.com (corresponding author), 'bradu.andrei.d@gmail.com, 'taranu@ce.tuiasi.ro,
dmbsinfex@yahoo.com, eilungu@ce.tuiasi.ro

Keywords: demolition solid waste, recycled steel fibers, durable rigid pavements, laboratory study.

\begin{abstract}
The paper presents the results and conclusions of investigations aiming to encourage the use of recycled materials, namely recycled aggregates (RA) and recycled steel fibers (RSF), in the construction of durable, economic and environmental friendly rigid pavements. To minimize and limit the negative effect of RA on the mechanical properties of cement concrete pavements, the research program considered both, development of technical solutions to improve the performance characteristics of RA particle, and RSF disperse reinforcement of concrete mixtures. Roller compacted concrete (RCC) cylindrical and prismatic test specimens manufactured with natural aggregates (NA) and original/performance improved RA have been subjected to flexure and compressive testes to evaluate the influence and contribution of developed technologies. Finally, guidelines and considerations for the use of RA in RCC and plain cement concrete (PCC) pavements are drawn.
\end{abstract}

\section{Introduction}

Construction of safe, economic and sustainable pavement infrastructures represents one important factor in the economic development of any country. Because pavement engineering is one of the major materials consumers in the construction industry [1], the design stage should be carried out aiming the use of alternative and renewable materials in order to meet the sustainable development concepts and to satisfy the extension process of national road network.

The broken cement concrete is one artificial renewable material resulted from demolitions of buildings or cement concrete pavements which, by recycling [2], could partially substitute the consumption of natural gravel/quarry aggregates. Also, in the frame of EcoLanes FP6 international project "Economical and Sustainable Pavement Infrastructure for Surface Transport" [3], the disperse reinforcement technology of cement concrete pavements using recycled steel fibers has been investigated, proving the improvement of mechanical behavior of rigid pavements.

Postdoctoral research program "Innovative technologies and logistical solutions for the reuse of demolition and construction waste in the construction of cement concrete and fiber reinforced cement concrete pavements" aims to study the influence of recycled aggregates (RA) and recycled steel fibers (RSF) on the performance characteristics of plain cement concrete (PCC) and roller compacted concrete (RCC) prismatic and cylindrical laboratory test specimens.

To improve the lower physico-mechanical characteristics of RA, namely reduced ware coefficients, durability, density or higher water absorption, and to enhance the control of RA mixture contaminants, several technical solutions and testing methodologies have been developed and detailed in the paper. 


\section{Materials and research methodology}

The study aims to identify the deficiencies of using RA mixtures on the properties of fresh and hardened state PCC and RCC. It is expected that, when partially replacing NA with RA in the manufacturing of cement concrete [4], the new concrete density lowers for both wet and hardened state, higher water content is needed for hydration of the mix and, therefore, lower strength performances of hardened cement concrete are recorded.

Investigated RA are obtained from crushing of demolished cement concrete from buildings [5]. After sorting the resulting RA mixture into 0-4, 4-8, 8-16 and 16-25 particle size classes, laboratory tests have been performed for both RA and quarry NA to determine and compare their performance properties, as shown in table 1.

Table 1 - Performance characteristics of RA and NA

\begin{tabular}{|c|c|c|c|c|c|c|c|}
\hline \multirow{2}{*}{$\begin{array}{c}\text { Aggregate } \\
\text { type }\end{array}$} & $\begin{array}{c}\text { Particle } \\
\text { size } \\
\text { class }\end{array}$ & $\begin{array}{c}\text { Crushing } \\
\text { coefficient, } \\
{[\%]}\end{array}$ & $\begin{array}{c}\text { LA wear } \\
\text { coefficient, } \\
{[\%]}\end{array}$ & $\begin{array}{c}\text { MicroDeval } \\
\text { wear coeff., } \\
{[\%]}\end{array}$ & $\begin{array}{c}\text { Dry state } \\
\text { density, } \\
{\left[\mathrm{Mg} / \mathrm{m}^{3}\right]}\end{array}$ & $\begin{array}{c}\text { Saturated } \\
\text { state density, } \\
{\left[\mathrm{Mg} / \mathrm{m}^{3}\right]}\end{array}$ & $\begin{array}{c}\text { Absorption } \\
\text { coeff., [\%] }\end{array}$ \\
\hline \multirow{3}{*}{ NA } & $4 / 8$ & 100 & 14.3 & - & 2.827 & 2.881 & 1.8 \\
\cline { 2 - 8 } & $8 / 16$ & 100 & 11.2 & 8.3 & 2.836 & 2.882 & 1.7 \\
\cline { 2 - 8 } & $16 / 25$ & 100 & 10.3 & - & 2.819 & 2.868 & 1.7 \\
\hline \multirow{3}{*}{ RA } & $4 / 8$ & 82 & 24.3 & - & 2.2163 & 2.3427 & 5.7 \\
\cline { 2 - 8 } & $8 / 16$ & 81 & 26.0 & 18.8 & 2.3034 & 2.4035 & 4.4 \\
\cline { 2 - 8 } & $16 / 25$ & 90 & 27.3 & - & 2.2539 & 2.3788 & 5.5 \\
\hline
\end{tabular}

As can be noticed, compared with NA, studied RA present lower wear resistance, reduced density and higher water absorption. Thus, compared with standard conditions for chippings and crushed gravel aggregates used in the construction of $1^{\text {st }}$ technical road class (highways, intense traffic roads), the determined characteristics meet successfully all the requirements for crushed gravel category, as shown in table 2 .

Table 2 - Standard performance characteristics of chippings and crushed gravel aggregates

\begin{tabular}{|c|c|c|c|c|}
\hline \multirow[b]{2}{*}{ NA type } & \multirow{2}{*}{$\begin{array}{c}\text { Particle } \\
\text { size class, } \\
\text { mm }\end{array}$} & \multicolumn{3}{|c|}{ Performance characteristic } \\
\hline & & $\begin{array}{c}\text { Crushing } \\
\text { coefficient, [\%] }\end{array}$ & $\begin{array}{c}\text { LA wear } \\
\text { coefficient, [\%] }\end{array}$ & $\begin{array}{c}\text { microDeval wear } \\
\text { coefficient, [\%] }\end{array}$ \\
\hline \multirow{3}{*}{ Chippings } & $4 / 8$ & \multirow{3}{*}{$\min .90$} & \multirow{3}{*}{$\max .18$} & - \\
\hline & $8 / 16$ & & & $\max .20$ \\
\hline & $16 / 25$ & & & - \\
\hline \multirow{3}{*}{$\begin{array}{c}\text { Crushed } \\
\text { gravel }\end{array}$} & $4 / 8$ & \multirow{3}{*}{$\min .65$} & $\max .35$ & - \\
\hline & $8 / 16$ & & $\max .30$ & - \\
\hline & $16 / 25$ & & $\max .25$ & - \\
\hline
\end{tabular}

For RA to represent a successful substituent of NA in pavement engineering, alternative technical solutions and additional testing methodologies must be developed for the improvement of RA particles/mixtures mechanical characteristics. Therefore, the research proposed and investigated several innovative solutions for the improvement of RA ware coefficients, mixture density uniformity check, control and removal of mixture main contaminants which are detailed in the next chapter.

RSF are resulted in the process of post-consumed tire recycling and, usually, treated as waste material. Tire recycling process [6] involves multiple shearing procedures (figure 1a) until shreds with dimensions varying from $10 \mathrm{~mm}$ to $50 \mathrm{~mm}$ are obtained. Using a granulator (figure $1 \mathrm{~b}$ ), resulting tire shreds are then reduced to rubber particles of $1 \ldots 6 \mathrm{~mm}$, textile and residual steel fibers. Following, a magnetic bell is used for the extraction of the metallic fibers. Investigated RSF present dimensions in length between $2 \mathrm{~mm}$ and $20 \mathrm{~mm}$ and are obtained by application of successive sieving procedures to the extracted fibers.

Studies conducted during EcoLanes research project demonstrated the benefits of RSF disperse reinforcement in means of mechanical behavior of PCC and RCC pavements [7]. Using RSF as reinforcement for cement concrete manufactured with RA can compensate the reduced mechanical strengths, or even overcome the performance of concrete manufactured entirely with NA. 

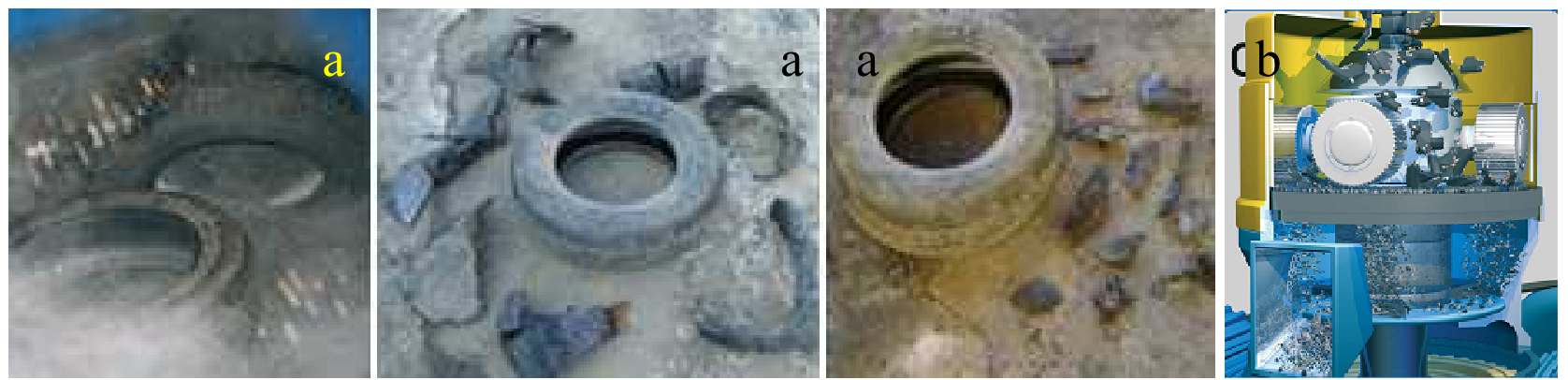

Fig. $1-a)$ Shredding process and tire shreds from first and second shredding procedure

b) Illustration of the granulator

\section{Technical solutions for improvement of RA performances}

Due to lower performance characteristics of RA, demolished concrete is often considered as adequate for use in low value construction works. In some European countries, which grant great consideration for the overexploitation of NA and environmental conservation, the recycling of construction and demolition wastes reaches up to $95 \%$. To achieve a higher economic value of RA and to stimulate the choice for demolished concrete recycling, technical solutions must be developed and applied to obtain RA with improved mechanical characteristics.

The pre-wear process of RA. RA obtained using a jaw crusher, present weak edges and surfaces where old mortar is present, due to uncontrolled cracking of the recycling concrete through the mortar matrix. Where RA present stone particles, the resulted surfaces/edges are smooth/firm as illustrated in figure $2 \mathrm{a}$.

By mixing RA with metallic cubes, the pre-ware process [8] aims to remove the micro-cracked edges and to improve the particle's surfaces leading to RA particles durability increase. The current analysis has been conducted using standard Los Angeles equipment as presented in figure $2 \mathrm{~b}$.
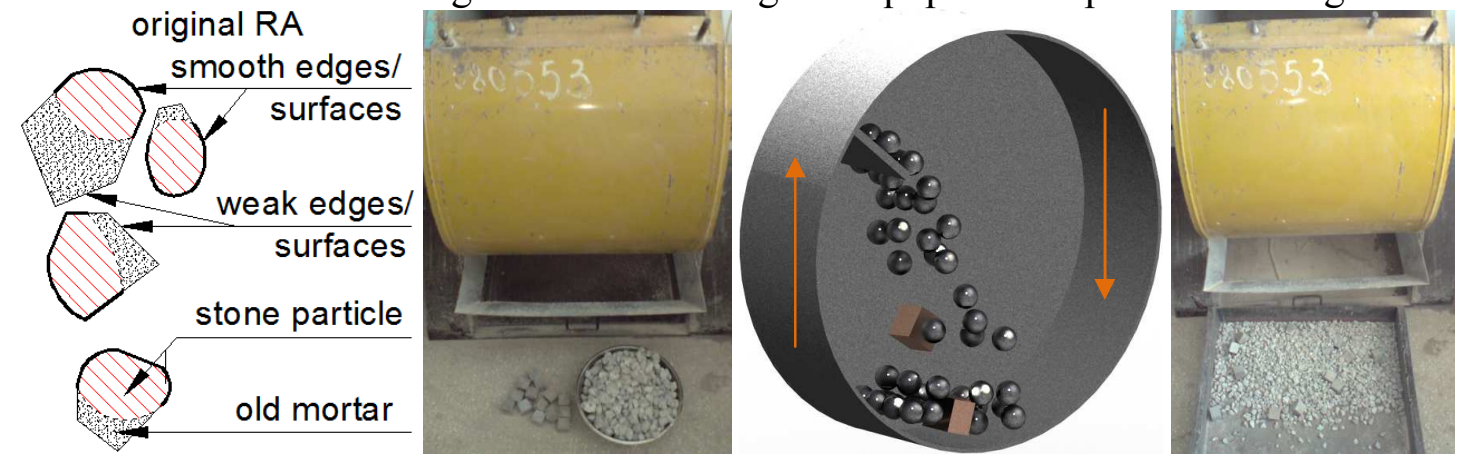

Fig. 2 - a) Smooth/weak edges/surfaces of original RA particles

b) The pre-ware process methodology

According to the testing procedure, $60 \mathrm{sec}$ and $120 \mathrm{sec}$ mixing periods have been adopted to investigate the influence on the RA particles durability. In figure 3 , the grading curve of the new RA mixture resulted for $60 \mathrm{sec}$ mixing period and performed for $8 / 16$ (a) and 16/25 (b) particle size classes, are presented.
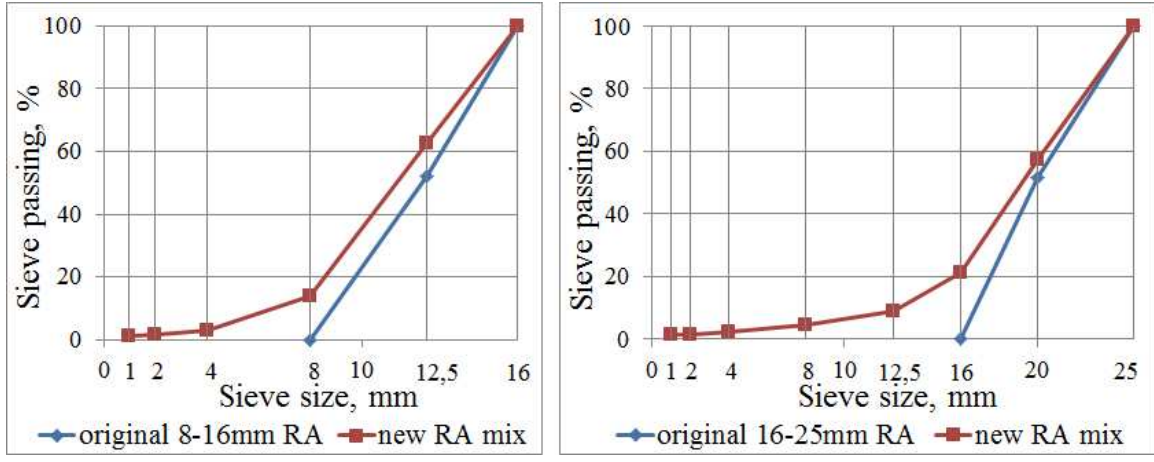

Fig. 3 - a) Smooth/weak edges/surfaces of RA particles

b) The pre-ware process methodology 
Table 3 presents the results regarding the mass loss of RA particles subjected to the procedure. Table 3-RA test specimen's mass loss

\begin{tabular}{|c|c|c|}
\hline Mixing period, [sec] & Particle size class, [mm] & Mass loss, [\%] \\
\hline \multirow{2}{*}{60} & $8 / 16$ & 16.45 \\
\cline { 2 - 3 } & $16 / 25$ & 21.01 \\
\hline \multirow{2}{*}{120} & $8 / 16$ & 22.16 \\
\cline { 2 - 3 } & $16 / 25$ & 23.74 \\
\hline
\end{tabular}

As the results show, the technology presents higher efficiency on 10 to $20 \mathrm{~mm}$ size particles and 16-25 particle size class specimen, due to lower particle number contained in the test specimen, lose weight more rapidly the $8-16 \mathrm{~mm}$ particle size class specimen.

Tests regarding Los Angeles (LA), micro-Deval (MD) and impact (SZ) wear coefficients have been performed for the new obtained RA and compared to original performance characteristics, as shown in table 4 , to evaluate the utility of developed methodology.

Table 4-Original/new RA performance characteristics

\begin{tabular}{|c|c|c|c|c|c|}
\hline RA type & Particle size class, [mm] & Mixing period, [sec] & LA, [\%] & MD, [\%] & SZ, [\%] \\
\hline \multirow{2}{*}{ original } & \multirow{2}{*}{$8 / 16$} & 0 & 26.0 & 18.8 & 19.8 \\
\cline { 1 - 5 } new & & 60 & 22.4 & 16.0 & 14.2 \\
\cline { 3 - 6 } new & & 120 & 21.0 & 14.6 & 13.0 \\
\hline
\end{tabular}

The investigations confirm that, by application of the developed technical solution on RA mixtures, the durability of RA particles is achieved. Although, the performance characteristics of recycled aggregates can usually be improved, the mechanical behavior of original NA used in the manufacturing of recycled concrete cannot be achieved.

Also, due to partial removal of old mortar from the stone particles, slight increase in density and decrease of water absorption of Ra particles are registered as indicated in table 5.

Table 5-Original and new
\begin{tabular}{|c|c|c|c|c|}
\hline RA type & $\begin{array}{c}\text { Mixing } \\
\text { period, }[\mathrm{sec}]\end{array}$ & $\begin{array}{c}\text { Dry Density, } \\
{\left[\mathrm{Mg} / \mathrm{m}^{3}\right]}\end{array}$ & $\begin{array}{c}\text { Saturated Density, } \\
{\left[\mathrm{Mg} / \mathrm{m}^{3}\right]}\end{array}$ & $\begin{array}{c}\text { Water } \\
\text { absorption, }[\%]\end{array}$ \\
\hline original & 0 & 2.3034 & 2.4035 & 4.34 \\
\hline new & 60 & 2.3401 & 2.4339 & 4.01 \\
\hline new & 120 & 2.3559 & 2.4471 & 3.87 \\
\hline
\end{tabular}

Density homogeneity check of RA mixtures. The use of RA in construction works involving precise performance characteristics for materials require rigorous control regarding the density homogeneity of RA mixtures. The concomitant recycling of different durability types of concrete can leads to large variations in terms of RA particle density.

Therefore, the research program developed a testing procedure and equipment [9] that can be used for the investigations of RA mixtures density homogeneity.

Figure 4 presents the testing equipment and the principle of the testing methodology requiring a vibration table and compressed air source connections.

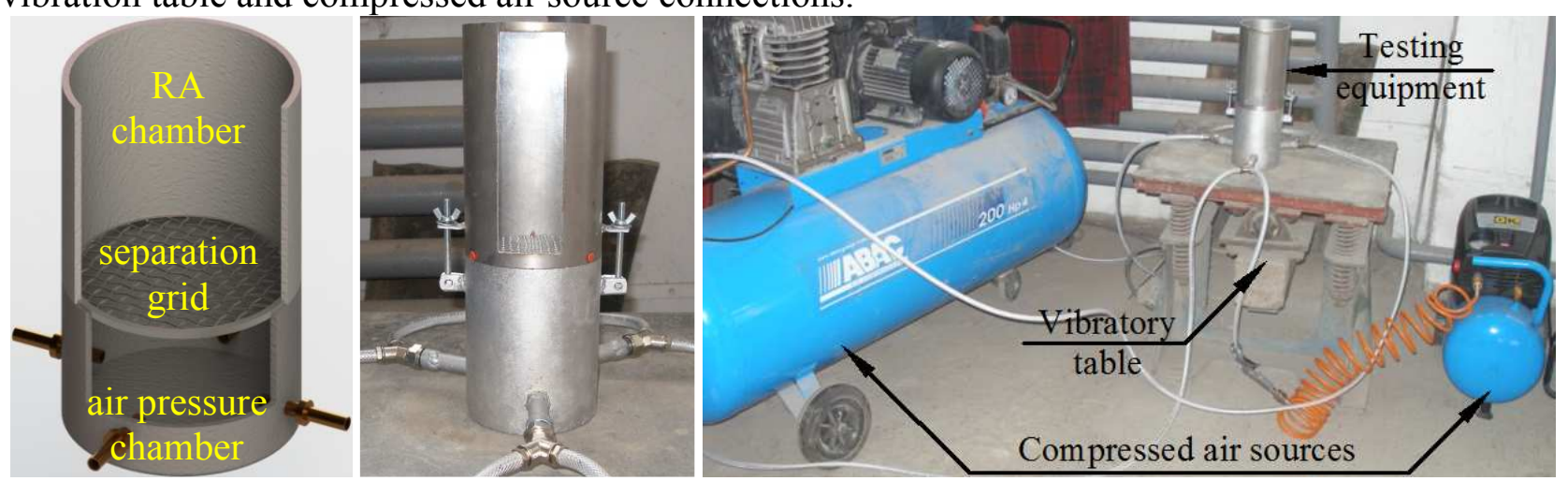

Fig. 4 - Developed laboratory equipment and testing methodology of RA density homogeneity

Due to lack of lightweight RA, crushed brick aggregates with density of $1.8-2.0 \mathrm{Mg} / \mathrm{m}^{3}$ have been used. As presented in figure 5a, the test started with the crushed brick aggregates on the bottom of the equipment's aggregate chamber over which RA have been placed. At the end of the, figure 5b, 
lower density aggregates are found on top of heavier particle test specimen. Same testing methodology has been performed for both, $10-12.5 \mathrm{~mm}$ and $12.5-14 \mathrm{~mm}$ particle size classes of RA and crushed brick aggregates.
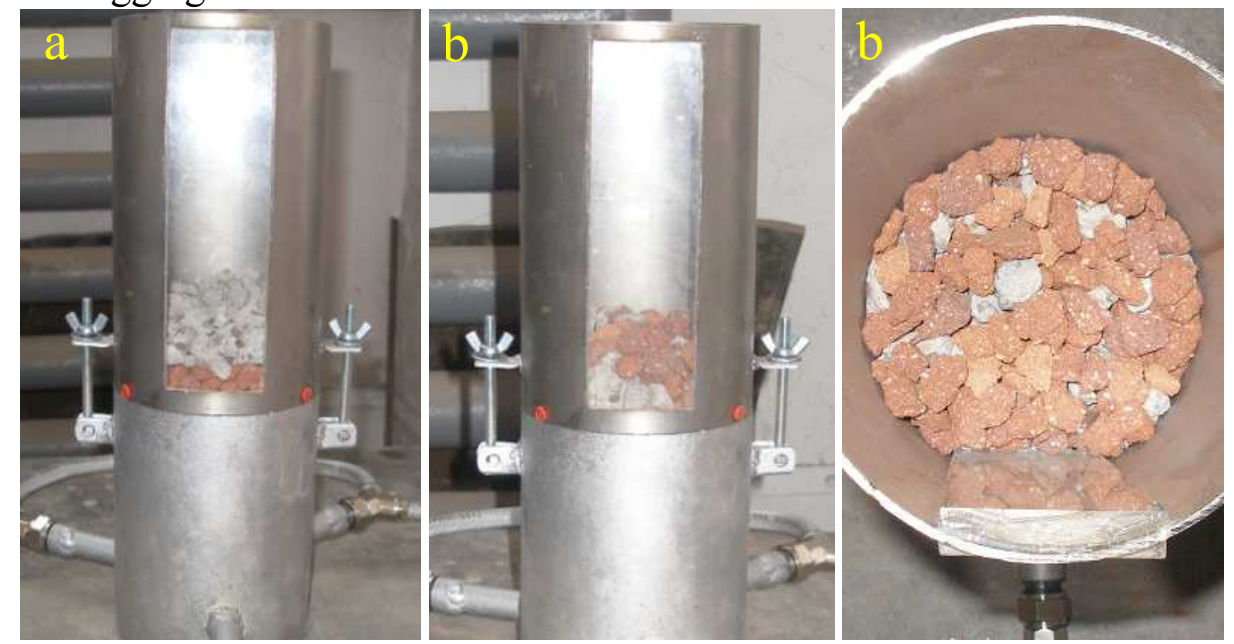

Fig. 5 -Density homogeneity test for separation of $R A$ and crushed brick aggregate mix

The developed testing procedure represents an investigation tool applicable for RA which can help when deciding the best field of use for investigated RA.

RA mixture decontamination. RA mixture contamination with other types of materials is often inevitable when dealing with industrial production. The color sorting technology, mainly used in food industry for the separation into different quality of seeds, rice, cereals and others, can be successfully adopted for the decontamination process of RA mixtures. Figure 6 presents the principle of the technology.

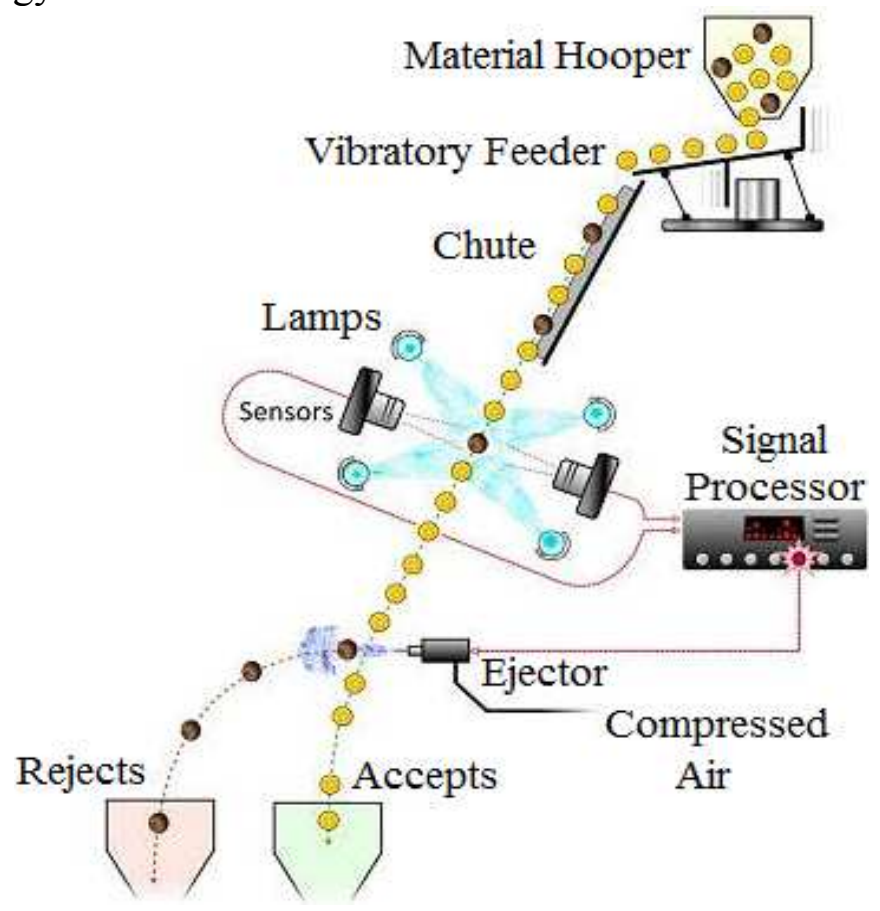

Fig. 6-The color sorting technology principle (http://www.satake.com.au)

\section{New design principles for the manufacturing of cement concrete using RA}

When dealing with RA in the manufacturing of new cement concrete compositions, the design methods applicable in the case of using only NA should be adapted to the main differences in characteristics of RA like particles density, water absorption and new concrete void content. Also, one new and unconventional mixing method for the component materials in the manufacturing process of concrete with RA has been identified to achieve higher mechanical strengths of hardened concrete. 
Replacement of NA with RA by density method. Actual composition design of road cement concrete requires the use of diverse NA, cement types, water and additives. Table 6 and table 7 present the calculations for the design of PCC and RCC compositions manufactured with NA.

Table 6-Design of PCC composition

\begin{tabular}{|c|c|c|c|c|c|c|}
\hline $\begin{array}{c}\text { Aimed } \\
\text { volume of } \\
\text { concrete, } \mathrm{V}_{\mathrm{c}}, \\
{\left[\mathrm{m}^{3}\right]}\end{array}$ & $\begin{array}{c}\text { Aimed } \\
\text { density of } \\
\text { concrete, } \rho_{\mathrm{c}}, \\
{\left[\mathrm{kg} / \mathrm{m}^{3}\right]}\end{array}$ & $\begin{array}{c}\text { Cement } \\
\text { dosage, } \\
\mathrm{C}, \\
{\left[\mathrm{kg} / \mathrm{m}^{3}\right]}\end{array}$ & $\begin{array}{c}\text { microAir } \\
\text { additive, } \\
\mathrm{M}_{\mathrm{a}}=0.2 \% \mathrm{C}, \\
{[\mathrm{kg}]}\end{array}$ & $\begin{array}{c}\text { Rheobuild } \\
572 \text { additive, } \\
\mathrm{R}_{\mathrm{a}}=0.7 \% \mathrm{C}, \\
{[\mathrm{kg}]}\end{array}$ & $\begin{array}{c}\text { Water } \\
\text { dosage, W, } \\
(\mathrm{W} / \mathrm{C} \text { ratio }), \\
{\left[\mathrm{kg} / \mathrm{m}^{3}\right]}\end{array}$ & $\begin{array}{c}\text { NA dosage, } \\
{\left[\mathrm{kg} / \mathrm{m}^{3}\right]}\end{array}$ \\
\hline 1 & 2500 & 330 & 0.66 & 2.31 & $145.53(0.45)$ & 2021.5 \\
\hline
\end{tabular}

Table 7 - Design of RCC composition

\begin{tabular}{|c|c|c|c|c|}
\hline $\begin{array}{c}\text { Aimed } \\
\text { volume of } \\
\text { concrete, } \mathrm{V}_{\mathrm{c}}, \\
{\left[\mathrm{m}^{3}\right]}\end{array}$ & $\begin{array}{c}\text { Aimed } \\
\text { density of } \\
\text { concrete, } \rho_{\mathrm{c}}, \\
{\left[\mathrm{kg} / \mathrm{m}^{3}\right]}\end{array}$ & $\begin{array}{c}\text { Cement } \\
\text { dosage, } \\
\mathrm{C}, \\
{\left[\mathrm{kg} / \mathrm{m}^{3}\right]}\end{array}$ & $\begin{array}{c}\text { Water } \\
\text { dosage, W, } \\
\left(6.5 \% \rho_{\mathrm{c}}\right), \\
{\left[\mathrm{kg} / \mathrm{m}^{3}\right]}\end{array}$ & $\begin{array}{c}\text { NA dosage, } \\
{\left[\mathrm{kg} / \mathrm{m}^{3}\right]}\end{array}$ \\
\hline 1 & 2250 & 300 & 149.5 & 1800.5 \\
\hline
\end{tabular}

When the influence of partial replacement of NA with RA, on the properties of hardened and fresh concrete, is investigated, one percentage is adopted, e.g. $40 \%$, of the total dosage of NA. Therefore, NA quantities of $808.6 \mathrm{~kg},(40 \% \cdot 2021.5 \mathrm{~kg})$ in the case of PCC composition, and $722.2 \mathrm{~kg},(40 \% \cdot 1800.5 \mathrm{~kg})$ for the RCC composition, need to be replaced with RA.

This approach of the problem is simple but slightly mistaken due to high difference in density of NA compared with RA. Investigating the case of PCC composition, by replacing $808.6 \mathrm{~kg}$ of NA, occupying $0.284 \mathrm{~m}^{3}$ in volume, with $808.6 \mathrm{~kg}$ of RA, filling $0.344 \mathrm{~m}^{3}$ in volume, leads to artificial increase of the manufactured concrete quantity from $1 \mathrm{~m}^{3}$ to $1.06 \mathrm{~m}^{3}$. This factor has little, but certain influence on the cement dosage adopted in the design process of the concrete composition, namely decrement of the cement dosage from $330 \mathrm{~kg} / \mathrm{m}^{3}$ to $311.3 \mathrm{~kg} / \mathrm{m}^{3}$. Same calculation process can be performed for the case of RCC composition leading to similar results. Off course, by lowering the cement dosage per $\mathrm{m}^{3}$ of manufactured concrete and the increase of RA/NA ratio by volume, decreased mechanical strength characteristics of hardened concrete are resulted.

The solution to solve this problem is to adopt the volumetric method of replacement of NA with RA which takes into consideration one of the main differences between the two materials, namely particle densities.

The method involves one simple step for the correct calculation of the RA quantity that is needed to partially replace the NA from a concrete composition using the following equation:

$$
M_{R A}=M_{N A} \times \frac{\rho_{R A}}{\rho_{N A}}
$$

where: $\quad M_{R A}-$ is the mass of the RA needed to replace the NA, in $\mathrm{kg}$;

$M_{N A}$ - is the mass of the NA needed to be replaced with RA, in $\mathrm{kg}$;

$\rho_{R A}-$ is the density of RA, in $\mathrm{kg} / \mathrm{m}^{3}$;

$\rho_{N A}-$ is the density of NA, in $\mathrm{kg} / \mathrm{m}^{3}$.

Therefore, to maintain constant the cement dosage per $\mathrm{m}^{3}$ and the RA/NA ratio, to replace $808.6 \mathrm{~kg}$ of NA with RA, a dosage of $667.0 \mathrm{~kg}$ RA is needed.

Water content design for RA concrete mix hydration. When dealing with new RA concrete compositions, the high water absorption of RA particles [10] must be taken into consideration to achieve the same concrete mix hydration designed for NA concrete composition. Equation 2 allows the calculation of the water dosage necessary to hydrate the RA concrete mix to the same level as NA concrete composition. Anyway, minor adjustment to the new water dosage may be needed, depending on the dry or wet type of the RA concrete mix, evaluated by preliminary laboratory tests performed on fresh concrete to ensure that standard requirements are satisfied. 


$$
W_{R A C}=W_{N A C}+M_{R A} \times W_{R A}-M_{N A} \times W_{N A} .
$$

where: $\quad W_{R A C}-$ is the water dosage needed for the RA concrete mix hydration, in $\mathrm{kg}$;

$W_{N A C}$ - is the water dosage necessary for the NA concrete mix hydration, in $\mathrm{kg}$;

$M_{R A}$ - is the mass of the RA which replace the NA, in $\mathrm{kg}$;

$M_{N A}$ - is the mass of the NA replaced by RA, in $\mathrm{kg}$;

$W_{R A}$ - is the water absorption of saturated state RA, in \%;

$W_{N A}$ - is the water absorption of saturated state NA, in $\%$.

Design of concrete void content when RA are used. Usually, void content of new concrete elements is a standard requirement to ensure proper control of different fresh or hardened state characteristics. When RA are used in the production of new concrete compositions, lower void content needs to be adopted in the design stage due to the presence of old mortar on the RA particles. By integrating the old mortar into the new concrete mortar, the void content increase of the new concrete element is achieved which can be easily anticipated by in the mix design process.

New component mix technique to maximize the RA concrete strengths. In actual practice, there are three known methods of incorporating RA with the new concrete composition [11], namely saturated with wet surfaces, saturated with dry surface and fully dry. Experimental investigations show that use of saturated and dry surfaces and fully dry RA to the manufacturing of cement concrete leads to the achievement of highest values for concrete strengths. The advantage of using saturated RA to the preparation of new concrete is that it allows normal hydration of the component mix, but the saturated surface of RA grants reduced bounding relation with the new matrix. Same benefit is met in the case of saturated and dry surfaces RA and, moreover, higher bounding relation between RA particles and the new concrete matrix is achieved. Greater RAconcrete matrix bounding results when dry RA are used, but higher moisture content of the concrete matrix is needed for later transfer to the dry RA particles, which can modify the behavior of fresh concrete.

Investigations undertaken in the frame of the postdoctoral research program identified one new mixing methodology [12] which combines the above mentioned advantages and confers even higher RA-concrete matrix bounding.

This is achieved by firstly adding into the mixer the dry RA particles with dimensions greater than $4 \mathrm{~mm}$ (e.g. $4-8 \mathrm{~mm}, 8-16 \mathrm{~mm}$ particle size classes). Then, one part enough to fully saturate all of the RA particles is taken from the total water dosage of the composition and is mixed with a small quantity of cement, taken also from the total cement dosage design for the composition, so that the cement particles are presented in a suspension state and do not form a paste. The prepared suspension is pored over the dry RA particles and the mixing process should be started for 1530sec. This procedure aims to fully saturate the RA particles and to form one full contact surface between RA particles and the cement matrix due to the presence of cement particles.

Table 8 presents the results obtained for RCC test specimens manufactured with fully saturated RA, dry RA and the above mentioned methodology involving cement suspension hydration.

Table 8-RCC mechanical strengths

\begin{tabular}{|c|c|c|c|c|}
\hline \multirow{2}{*}{$\begin{array}{c}\text { RCC } \\
\text { mix type }\end{array}$} & \multicolumn{2}{|c|}{$\begin{array}{c}\text { Compressive strength } \\
\text { on specimens, [MPa] }\end{array}$} & $\begin{array}{c}\text { Bending } \\
\text { strength, [MPa] }\end{array}$ & $\begin{array}{c}\text { Elasticity } \\
\text { modulus, } \\
{[\mathrm{MPa}]}\end{array}$ \\
\cline { 2 - 4 } & Cylindrical & Prism ends & Prism & 17,678 \\
\hline fully saturated and wet surface RA & 8.28 & 9.79 & 1.96 & 18,415 \\
\hline dry RA & 10.55 & 14.52 & 2.75 & 18,258 \\
\hline RA saturated with cement suspension & 11.29 & 19.34 & 3.65 & 15 \\
\hline
\end{tabular}

Therefore, the influence of the developed mixing methodology on the strength of the hardened $\mathrm{RCC}$ is significant compared with the other conventional techniques due to the increase of the bond contact between RA particles and new concrete matrix. However, this significant improvement is specific, as shown, for dry concrete mixes (RCC). 
Future studies will investigate the usefulness of the technology in the case of wet concrete mix where lower improvement level is expected due to high hydration ratio of the new concrete mortar.

\section{RCC manufactured with recycled materials laboratory experimental case}

RCC technology has been initially developed for the building of dams and adopted later in agricultural and forest roads construction. Following researches proved that RCC presents a viable alternative for conventional concrete pavements due to low requirements for equipment and training personnel [3]. The RCC can be casted using conventional asphalt pavers and steel roller compactors used in asphalt engineering and the constructed layers can be subjected immediately to traffic. Although, for high speed technical road class it is recommended the protection of the RCC using reduced thickness asphalt layer.

To evaluate the benefits of the developed technical solutions and the new design principles, the research aims to produce and test PCC and RCC laboratory specimens manufactured with 100\% NA, for reference results, and $60 \% / 40 \%$ ratio of AN/AR. At the date of the article, only the RCC type of concrete has been investigated.

As mixture binder, the use of DOROPORT TB 25, CEM I 42.5R and CEM II BM S-LL 32.5R has been studied aiming to extent the field of use of RCC pavements. Also, to compensate the strength reduction of RCC manufactured with RA, disperse reinforcement using RSF has been included in the study.

Table 9 presents the grading distribution of used particle size classes of NA and RA, the recommended limits of the RCC grading curve and the adopted aggregate proportions, in percentage, for the manufacturing of RCC compositions.

Table 9 - Grading distributions of NA and RA, grading limits of RCC and RCC compositions

\begin{tabular}{|c|c|c|c|c|c|c|c|c|c|}
\hline \multirow{3}{*}{ Aggregate types } & \multirow{2}{*}{\multicolumn{7}{|c|}{ Grading sieve passing, $[\%]$}} & \multicolumn{2}{|c|}{ RCC type, $[\%]$} \\
\hline & & & & & & & & \multirow{2}{*}{$\begin{array}{c}100 \% \text { NA } \\
0 \% \text { RA }\end{array}$} & \multirow{2}{*}{$\begin{array}{l}60 \% \text { NA } \\
40 \% \text { RA }\end{array}$} \\
\hline & 0,20 & 0,63 & 20 & 2 & 4 & 8 & 16 & & \\
\hline Natural Sand 0-4 & 17.60 & 67.30 & 73.60 & 82.90 & 96.50 & 100 & 100 & 35 & 35 \\
\hline Crushed Sand 0-4 & 14.25 & 31.70 & 43.50 & 69.70 & 97.75 & 100 & 100 & 20 & 5 \\
\hline Chippings 4-8 & 1.20 & 1.80 & 2.20 & 4.05 & 17.05 & 96.85 & 100 & 25 & 10 \\
\hline Chippings 8-16 & 0.95 & 1.40 & 1.60 & 2.25 & 3.85 & 17.65 & 98.80 & 20 & 10 \\
\hline RA Sand 0-4 & 13.10 & 33.70 & 43.30 & 63.30 & 94.50 & 100 & 100 & 0 & 15 \\
\hline RA 4-8 & 0.00 & 0.00 & 0.00 & 0.70 & 2.00 & 100 & 100 & 0 & 12.5 \\
\hline RA 8-16 & 0.00 & 0.00 & 0.00 & 0.00 & 0.70 & 7.70 & 99.40 & 0 & 12.5 \\
\hline RCC limits & $9-30$ & $20-40$ & $27-47$ & $38-55$ & $44-65$ & $72-90$ & $95-100$ & & \\
\hline
\end{tabular}

To ensure that maximum compaction degree is conferred to the test specimens, modified Proctor test has been performed for both, NA and $60 \% / 40 \%$ of NA/RA RCC mixtures, the results being presented in table 10 [4].

Table 10-Modified Proctor test results for optimum moisture content of RCC compositions

\begin{tabular}{|c|c|c|c|c|c|c|c|}
\hline RCC & Mixture density & \multicolumn{7}{|c|}{ Mixture moisture content, [\%] } \\
\cline { 3 - 8 } mixture type & characteristic & 5 & 6 & 7 & 8 & 9 & 10 \\
\hline $100 \% \mathrm{NA}$ & Wet, $[\mathrm{Mg} / \mathrm{m} 3]$ & 2.271 & 2.310 & $\mathbf{2 . 3 3 8}$ & 2.322 & - & - \\
\cline { 2 - 9 } $0 \% \mathrm{RA}$ & Dry, $[\mathrm{Mg} / \mathrm{m} 3]$ & 2.141 & 2.156 & 2.171 & 2.167 & - & - \\
\hline $60 \% \mathrm{NA}$ & Wet, $[\mathrm{Mg} / \mathrm{m} 3]$ & 2.063 & 2.077 & 2.100 & 2.136 & $\mathbf{2 . 1 5 0}$ & 2.142 \\
\cline { 2 - 9 } $40 \% \mathrm{RA}$ & Dry, $[\mathrm{Mg} / \mathrm{m} 3]$ & 1.930 & 1.933 & 1.938 & 1.950 & 1.957 & 1.942 \\
\hline
\end{tabular}

As noticed, AN/AR RCC variant presents lower mixture density and requires increased moisture content to compensate the high water absorption of replacing RA.

As shown in figure 5, three cylindrical/prismatic specimens have been manufactured (figure 5a) for each RCC composition and subjected to testing (figure 5b) procedure for the evaluation of the modulus of elasticity and compressive/bending strength. 

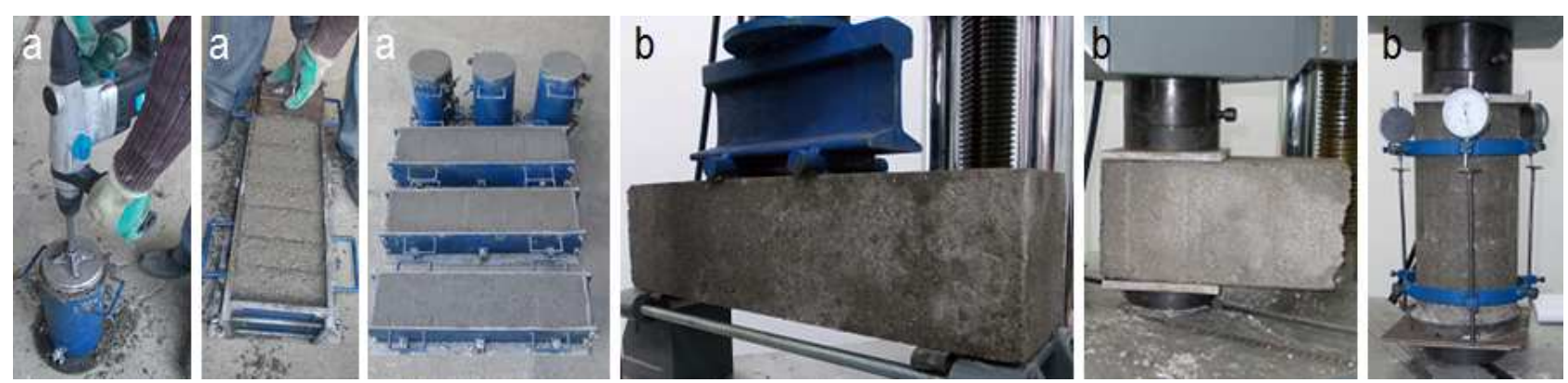

Fig. 7 - Manufacturing (a) and testing (b) procedures of prismatic and cylindrical specimens

Table 11 presents the mechanical strength properties of reference RCC, RA manufactured RCC and SRF reinforced RCC compositions [13] achieved for various hardening age.

Table 11 -Results of tests performed on hardened RCC compositions

\begin{tabular}{|c|c|c|c|c|c|c|c|c|}
\hline \multirow[t]{2}{*}{ RCC type } & \multirow{2}{*}{$\begin{array}{c}\text { AN/AR } \\
\text { ratio, } \\
{[\% / \%]}\end{array}$} & \multirow[t]{2}{*}{ Binder type } & \multirow{2}{*}{$\begin{array}{l}\text { Binder } \\
\text { dosage, } \\
{\left[\mathrm{kg} / \mathrm{m}^{3}\right]}\end{array}$} & \multirow{2}{*}{$\begin{array}{c}\text { Testing } \\
\text { age, } \\
\text { [days] }\end{array}$} & \multicolumn{2}{|c|}{$\begin{array}{c}\text { Compression strength, } \\
{[\mathrm{MPa}]}\end{array}$} & \multirow{2}{*}{$\begin{array}{c}\text { Bending } \\
\text { strength, } \\
{[\mathrm{MPa}]}\end{array}$} & \multirow{2}{*}{$\begin{array}{c}\text { Elasticity } \\
\text { modulus, } \\
\text { [MPa] }\end{array}$} \\
\hline & & & & & Cylinders & Prism ends & & \\
\hline $\mathrm{RCC}$ & $100 / 0$ & CEM I 42.5R & 300 & 28 & 11.78 & 24.31 & 4.09 & 18,300 \\
\hline $\mathrm{RCC}$ & $60 / 40$ & CEM I 42.5R & 300 & 28 & 11.29 & 19.34 & 3.65 & 18,258 \\
\hline $\mathrm{RCC}+\mathrm{RSF}$ & $60 / 40$ & CEM I 42.5R & 300 & 28 & 12.43 & 19.09 & 3.90 & 15,252 \\
\hline $\mathrm{RCC}$ & $100 / 0$ & CEM II 32.5R & 300 & 28 & 17.57 & 23.46 & 5.05 & 24,352 \\
\hline $\mathrm{RCC}$ & $60 / 40$ & CEM II 32.5R & 300 & 28 & 16.70 & 21.15 & 4.01 & 23,449 \\
\hline $\mathrm{RCC}+\mathrm{RSF}$ & $60 / 40$ & CEM II 32.5R & 300 & 28 & 17.59 & 23.80 & 5.26 & 20,783 \\
\hline $\mathrm{RCC}$ & $100 / 0$ & Doroport TB 25 & 250 & 28 & 9.61 & 14.88 & 3.52 & 13,268 \\
\hline RCC & $100 / 0$ & Doroport TB 25 & 250 & 42 & 10.52 & 17.16 & 3.76 & 18,241 \\
\hline $\mathrm{RCC}$ & $100 / 0$ & Doroport TB 25 & 350 & 28 & 13.07 & 17.28 & 3.91 & 19,577 \\
\hline $\mathrm{RCC}$ & $100 / 0$ & Doroport TB 25 & 350 & 42 & 15.27 & 19.53 & 4.10 & 20,334 \\
\hline RCC & $60 / 40$ & Doroport TB 25 & 300 & 28 & 10.84 & 16.81 & 2.92 & 17,362 \\
\hline RCC & $60 / 40$ & Doroport TB 25 & 300 & 42 & 12.08 & 18.72 & 3.42 & 18,273 \\
\hline $\mathrm{RCC}+\mathrm{RSF}$ & $60 / 40$ & Doroport TB 25 & 300 & 28 & 12.05 & 17.52 & 3.79 & 13,941 \\
\hline $\mathrm{RCC}+\mathrm{RSF}$ & $60 / 40$ & Doroport TB 25 & 300 & 42 & 12.70 & 18.04 & 4.00 & 14,842 \\
\hline
\end{tabular}

\section{Discussions}

Conducted laboratory tests performed on hardened RCC compositions prove that inferior types of binders (CEM II BM S-LL 32.5R and DOROPORT TB 25), due to the dry type of the RCC mixtures which cannot allow full binder hydration when using high performance binders, present higher compatibility for use to the production of RCC pavements.

By replacing $40 \%$ of NA with studied RA, the mechanical strengths of investigated RCC alternatives have decreased, on average, by only $5-10 \%$ with no influence on the modulus of elasticity.

The disperse RSF reinforcement of RCC manufactured with RA leads to benefits as the reduction of the elasticity modulus and the recovery/overcoming NA RCC strengths.

\section{Conclusions}

Extension the field of use of RA in pavement engineering to high value concrete elements could lead to the increase of demolished cement concrete recycling rate and, therefore, to the protection of the environment and human health.

Due to different mechanical behavior of RA compared with NA, innovative technical solutions need to be developed to gain proper control and to improve the physico-mechanical properties of RA particles and mixtures.

New design methods are required for the implementation of RA as a viable alternative to NA to the production of high performance cement concrete which take into consideration the new developed technologies for the improvement or RA mixtures/particles and proper adapt the RA performance characteristics to maximize hardened concrete strength. 
The presented research program developed three technologies which help control the durability/quality of RA particles/mixtures and four design principles for the use of RA to concrete manufacturing and have certain influence on the improvement of concrete performances.

Acknowledgment: This paper was supported by the project "Development and support of multidisciplinary postdoctoral programmes in major technical areas of national strategy of Research - Development - Innovation" 4D-POSTDOC, contract no. POSDRU/89/1.5/S/52603, project cofunded by the European Social Fund through Sectorial Operational Programme Human Resources Development 2007-2013.

\section{References}

[1] M.T. Muscalu, N. Taranu, Use of recycled materials in pavement construction, Proceedings of the $8^{\text {th }}$ International Symposium "Technology and innovation in transportation infrastructure", Highway and Bridge Engineering 2010, Iasi, Romania, (2010), 15-21.

[2] $* *$ Directive 2008/98/EC of the European Parliament and of the Council on waste, 19 November.

[3] T. Varlan, C. Zbarnea, C. Bulau, M.T. Muscalu, Construction on D.R.D.P. Iasi activity area of roller compacted concrete pavement structures disperse reinforced with recycled fibers derived from tire recycling, in Romanian, XIIIth National Roads and Bridge Congress, vol. II, Poiana Brasov, Romania, (2010), 53-65.

[4] M.T. Muscalu, R. Andrei, M. Budescu, N. Taranu, Recycled aggregates and rigid pavement engineering, Journal of Applied Engineering Sciences, vol. 2(15), issue2_2012, (2012), 61-68.

[5] M.T. Muscalu, R. Andrei, Use of recycled aggregates in rigid pavement construction, The Bulletin of the Polytechnic Institute of Jassy, Construction Architecture Section, Tome LVII (LXI), Fasc. 2, (2011), 69-78.

[6] E. Musacchi, P. Iacobucci, Deliverable 1.2 Classification of fibers from different mechanical treatments and the reasons for fiber balling, EcoLanes WP1 2nd Management Meeting, Antalya, Turkey, 5-7 October 2007.

[7] M.T. Muscalu, Accelerated load testing of rigid structures under simulated traffic, Proceedings of the $6^{\text {th }}$ International Symposium "Transportation Infrastructures New Developments", Highway and Bridge Engineering 2008, Iasi, Romania, (2008), 255-266.

[8] M.T. Muscalu, Method for improvement of some performances of recycled aggregates by application of a wear, Patent request OSIM no A/00356 from 21.05.2012.

[9] M.T. Muscalu, Laboratory equipment for the evaluation of the density homogeneity of recycled aggregates, Patent request OSIM no A/00826 from 15.11.2012.

[10] T.C. Hansen, Recycling of Demolished Concrete and Masonry, Report of Technical Committee 37-DRC, RILEM Report 6, 1992.

[11] C.S. Poon, Z.H. Shui, L. Lam, H. Fok, S.C. Kou, Influence of moisture states of natural and recycled aggregates on the slump and compressive strength of concrete, Cement and Concrete Research, Vol. 34, Issue 1, (2004), 31-36.

[12] M.T. Muscalu, Mixing method for bond improvement of recycled aggregates surfaces to the new cement concrete matrix, Patent request OSIM no A/00138 from 08.02.2013.

[13] M.T. Muscalu, R. Andrei, M. Budescu, N. Taranu, E. Florescu, Use of recycled materials in the construction of roller compacted concrete (RCC) pavements, Advanced Materials Research Vol. 649, Trans Tech Publications, Switzerland, doi: 10.4028/www.scientific.net/ AMR.649.262, (2013), 262-265 